\title{
Influence of Chemical Composition on the Catalytic Activity of Small Bimetallic FeRu Nanoparticles for Fischer-Tropsch Syntheses
}

\author{
Anca Meffre $\cdot$ Viacheslav Iablokov $\cdot$ Yizhi Xiang $\cdot$ Roland Barbosa \\ Pier Francesco Fazzini • Vinciane Kelsen • Norbert Kruse • \\ Bruno Chaudret
}

Received: 27 August 2014/ Accepted: 31 October 2014/Published online: 19 November 2014

(C) Springer Science+Business Media New York 2014

\begin{abstract}
FeRu nanoparticles were prepared according to an organometallic route using $\left\{\mathrm{Fe}\left[\mathrm{N}\left(\mathrm{Si}\left(\mathrm{CH}_{3}\right)_{3}\right)_{2}\right]_{2}\right\}_{2}$ and $\left(\eta_{4}-1,5\right.$-cyclooctadiene $)\left(\eta_{6}-1,3,5\right.$-cyclooctatriene $)$ ruthenium(0) $\mathrm{Ru}(\mathrm{COD})(\mathrm{COT})$ precursors followed by their insertion into a mesoporous MCF-17 support host. The resulting nanoparticles had a uniform size of approximately $2 \mathrm{~nm}$, with a relative $\mathrm{Ru}$ amount of up to 33 at.\%. Steadystate Fischer-Tropsch catalysis at 6 bar total pressure $\left(\mathrm{H}_{2} /\right.$ $\mathrm{CO}=1: 1)$ demonstrated light olefins production with a selectivity close to $50 \%$ (ex. $\mathrm{CO}_{2}$ ) for catalysts with low $\mathrm{Ru}$ content (5 at.\%). The selectivity pattern changed to long chain-paraffin production with increasing $\mathrm{Ru}$ amounts. These catalysts were also more active than those containing few $\mathrm{Ru}$. X-ray photoelectron spectroscopy showed under-parity $\mathrm{Ru}$ amounts to effectively cover the surface of $\mathrm{Fe}$ nanoparticles. The nanoparticle distribution inside the MFC-17 host was characterized by microtomia/ transmission electron microscopy.
\end{abstract}

Electronic supplementary material The online version of this article (doi:10.1007/s10562-014-1421-3) contains supplementary material, which is available to authorized users.

A. Meffre · P. F. Fazzini · V. Kelsen · B. Chaudret $(\square)$ Laboratoire de Physique et Chimie des Nano Objets, INSA, Université de Toulouse, 135, avenue de Rangueil, 31077 Toulouse, France

e-mail: bruno.chaudret@insa-toulouse.fr

V. Iablokov $\cdot$ Y. Xiang $\cdot$ R. Barbosa $\cdot$ N. Kruse Chemical Physics of Materials, Université Libre de Bruxelles, Campus Plaine, CP 243, 1050 Brussels, Belgium

e-mail: norbert.Kruse@wsu.edu

Y. Xiang $\cdot$ R. Barbosa $\cdot$ N. Kruse

Catalysis for Clean Energy \& Environment, Voiland School of Chemical Engineering, Washington State University, PO Box 646515, Pullman, WA 99164-6515, USA
Keywords Nanoparticles - Colloidal synthesis Fischer-Tropsch Heterogeneous catalysis · FeRu

\section{Introduction}

The Fischer-Tropsch synthesis (FTS) is attracting continued interest since it allows the conversion of syngas $(\mathrm{CO} /$ $\mathrm{H}_{2}$ ) into hydrocarbon-derived fuels using non-petroleum feedstocks, such as natural gas, coal or biomass. To date, commercial processes use iron and cobalt-based catalysts. $\mathrm{Ru}$ metal is likewise FT-active and has chain-lengthening properties superior to those of iron and cobalt.

Hydrocarbon products in FTS usually follow the Anderson-Schulz-Flory (ASF) distribution, which is determined by a polymerization-type mechanism involving the regioselective repetitive insertion of a monomer into the growing chain. The chain growth probability $(\alpha)$, usually expressed in kinetic terms by relating the rate constant of chain propagation to that of chain termination, is influenced by various factors such as the process conditions or the choice of catalyst and chemical promoters [1,2]. Due to the polymerization-type mechanism of chain growth, a range of $C_{n}$ products are formed rather than a single-n product. In this respect, the ASF distribution is unselective. However, in recent years, much has been learned about the design of catalysts favoring either short-chain or longchain hydrocarbons production [3-7]. Furthermore, the FT synthesis produces not only paraffinic hydrocarbons; terminal olefins and oxygenates may be likewise produced with variable chain length [8-11].

Tailoring catalysts for specific applications in FT synthesis may either be based on exploring particle size and morphology effects or 'alloying' relevant metals and metal oxides. Therefore, controlling the nucleation and growth of 
metallic nanoparticles and designing size- and composition-variable catalysts are crucial for the development of high performance FT catalysts.

Particle size effects were previously reported by various authors [4, 12-15], mainly for cobalt [16] and ruthenium metals [17-19]. All these studies showed that the catalytic activity is independent of the cobalt or ruthenium particle size in the size range from 9 to $200 \mathrm{~nm}$, while smaller metal nanoparticles $(<6 \mathrm{~nm})$ show higher selectivity towards methane formation.

Iron based catalysts, on the other hand, attracted an ever-lasting attention since the early days of FT catalysis because iron metal is cost-efficient, shows little toxicity and is easily accessible due to its abundance. Although iron-based catalysts are generally less active than Co and $\mathrm{Ru}$ ones, they may have advantages with respect to olefin production. Recently, the group of de Jong [20, 21] reported evidence for a size effect of iron nanoparticles (NPs) as catalysts for FT synthesis. The same study claimed a sixfold to eightfold increase for the initial activity when decreasing the average size of iron NPs from 7 to $2 \mathrm{~nm}$, while the selectivity for methane and lower olefins formation were not affected.

Despite the recent progress in tuning the activity and selectivity of monometallic catalysts in FT synthesis, further efforts are necessary to meet future challenges and specifications. In this context iron-ruthenium NPs may be considered attractive. Such FeRu catalysts were shown to be interesting not only in relation to FT synthesis [22-25], but also for the water-gas shift reaction [26] and the selective hydrogenation of unsaturated aldehydes and ketones [27, 28]. Despite this interest, only a few reports were published so far on the synthesis of FeRu nanoparticles. The main preparation routes for FeRu alloys involve co-impregnation of a solid support with solutions of metallic salts, ionic liquids and their reduction [27-30], microwave irradiation $[26,31]$ or metal organic chemical vapor deposition (MOCVD) [32]. Very recently, Kelsen et al. reported a new organometallic approach for the synthesis of FeRu bimetallic nanoparticles under mild conditions [33, 34]. This approach which is based on the reduction of various organometallic precursors in the presence of a reducing agent under mild conditions was originally developed in the Toulouse group for the synthesis of monodisperse magnetic nanoparticles which can be mono or bimetallic [35-37], or even associated with a main group element to form e.g. carbides [38]. Thus, for the synthesis of iron-based nanoparticles, the iron bis(amide) complex $\left\{\mathrm{Fe}\left[\mathrm{N}\left(\mathrm{SiMe}_{3}\right)_{2}\right]_{2}\right\}_{2}\left(\mathrm{Me}=\mathrm{CH}_{3}\right)$ was chosen due to its reactivity and versatility for producing welldefined nanostructures with unprecedented magnetic [35$44]$, catalytic [33, 34] or hyperthermia properties [38-42].
In a previous paper [33], the Toulouse group reported on the preparation of bimetallic FeRu nanoparticles through co-decomposition of two organometallic precursors, $\{\mathrm{Fe}[\mathrm{N}$ $\left.\left.\left(\mathrm{Si}\left(\mathrm{CH}_{3}\right)_{3}\right)_{2}\right]_{2}\right\}_{2}$ and $\left(\eta^{4}-1,5\right.$-cyclooctadiene $)\left(\eta^{6}-1,3,5\right.$-cyclooctatriene) ruthenium(0) $\mathrm{Ru}(\mathrm{COD})(\mathrm{COT})$, under $\mathrm{H}_{2}$ at $150{ }^{\circ} \mathrm{C}$ in mesitylene. The NPs were fully characterized by combining transmission electron microscopy (TEM), high resolution electron microscopy (HREM), wide angle X-ray scattering (WAXS) and Quantum design model MPMS 5.5 SQUID magnetometry.

The present work provides a feasibility study with respect to catalytic applications. We shall demonstrate that bimetallic FeRu nanoparticles can be successfully inserted into a mesoporous MCF-17 host structure and characterized for their catalytic performance in FT synthesis. Emphasis will be laid on revealing the influence of varying relative amounts of $\mathrm{Ru}$ in FeRu on the catalytic activity and selectivity. We thereby highlight the possibility of using bimetallic FeRu nanoparticles, prepared according to organometallic recipes, in heterogeneous catalysis without employing impregnation-decomposition-calcination cycles as encountered in classical procedures using inorganic metal precursors.

\section{Experimental Section}

Three nanoparticle samples were prepared according to a previously reported route by reacting the two organometallic precursors $\left\{\mathrm{Fe}\left[\mathrm{N}\left(\mathrm{Si}\left(\mathrm{CH}_{3}\right)_{3}\right)_{2}\right]_{2}\right\}_{2}$ and $\left(\eta^{4}-1,5\right.$-cyclooctadiene $)\left(\eta^{6}-1,3,5\right.$-cyclooctatriene) ruthenium $(0) \mathrm{Ru}(\mathrm{COD})$ (COT), under $\mathrm{H}_{2}$ at $150{ }^{\circ} \mathrm{C}$ in mesitylene. The resulting

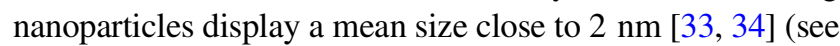
Fig. 1 Supporting Information) and a composition reflecting that of the initial solution. The three samples differ in the relative amount of Ru: FeRu1 (Ru: 5 at.\% or molar ratio of $\mathrm{Fe}: \mathrm{Ru}$ as 1:0.05), FeRu2 (Ru: 17 at.\% or molar ratio of Fe:Ru as 1:0.2) and FeRu3 (Ru: 33 at.\% or molar ratio of $\mathrm{Fe}: \mathrm{Ru}$ as 1:0.5). FeRu nanoparticles were introduced into mesoporous silica (MCF-17) under sonication for $1 \mathrm{~h}$ using a solution of NPs in mesitylene. The resulting supported NPs were dried at $100{ }^{\circ} \mathrm{C}$ for $40 \mathrm{~min}$. Fe metal loadings were determined by atomic absorption spectroscopy (AAS). Overall metal amounts were calculated by taking into account the relative amounts of $\mathrm{Ru}$ complexes. To receive information about the metal dispersion in MCF-17, the used catalysts (i.e. after reaction studies) were spread into a resin and subjected to a microtomy experiment followed by TEM imaging.

High-pressure tests were performed in a fixed-bed plugflow reactor consisting of a quartz tube $\left(\mathrm{d}_{\text {inner }}=7 \mathrm{~mm}\right)$ inside a stainless steel housing. In a typical experimental 
Table 1 Summarized data for catalytic properties of iron catalysts in high-pressure Fischer-Tropsch reaction (selectivities towards different products are shown in wt $\%$ )

\begin{tabular}{|c|c|c|c|c|c|c|c|c|c|c|}
\hline \multirow[t]{2}{*}{ Sample } & \multirow[t]{2}{*}{ At.\% Ru (\%) } & \multirow{2}{*}{$\begin{array}{l}\text { Reaction rate, } \\
\left(\text { molecules }_{\mathrm{CO}} \mathrm{nm}^{-2} \mathrm{~s}^{-1}\right)\end{array}$} & \multicolumn{6}{|c|}{ Selectivity (\%) } & \multirow[t]{2}{*}{$\alpha \mathrm{RH}$} & \multirow[t]{2}{*}{$\alpha \mathrm{R}=$} \\
\hline & & & $\mathrm{CH}_{4}$ & $\mathrm{C}_{2}-\mathrm{C}_{4}$ & $\mathrm{C}_{2}=\mathrm{C}_{4}$ & $\mathrm{C}_{5+}$ & RO & $\mathrm{CO}_{2}$ & & \\
\hline FeRu1/MCF-17 & 5 & 0.012 & 26 & 3 & 38 & 14 & - & 19 & - & 0.39 \\
\hline FeRu2/MCF-17 & 17 & 0.057 & 14 & 16 & 15 & 41 & 7 & 7 & 0.70 & 0.48 \\
\hline FeRu3/MCF-17 & 33 & 0.253 & 13 & 16 & 13 & 40 & 8 & 9 & 0.70 & 0.52 \\
\hline FeRu1/MCF-17 & & 0.010 & 32 & 4 & 47 & 17 & - & \multirow{3}{*}{\multicolumn{3}{|c|}{$\begin{array}{l}\mathrm{CO}_{2} \text { is excluded from the selectivity. } \\
\text { Surface rate values are based on } \mathrm{CO} \\
\text { conversion to hydrocarbon formation } \\
\text { only }\end{array}$}} \\
\hline FeRu2/MCF-17 & & 0.053 & 15 & 17 & 15 & 46 & 7 & & & \\
\hline FeRu3/MCF-17 & & 0.230 & 14 & 17 & 14 & 45 & 9 & & & \\
\hline
\end{tabular}

$\mathrm{H}_{2}: \mathrm{CO}=1: 1,300{ }^{\circ} \mathrm{C}, 6$ bar, $\mathrm{D}_{\text {total }}=60 \mathrm{~mL} \mathrm{~min}^{-1}$

procedure, an appropriate amount of catalyst $(0.25-0.60 \mathrm{~g})$ was loaded in the reactor followed by a mild activation with $\mathrm{H}_{2}$ at 1 bar $\left(40 \mathrm{~mL} \mathrm{~min}{ }^{-1}\right)$ and $350{ }^{\circ} \mathrm{C}$ during $1 \mathrm{~h}$. The reactor was subsequently cooled to ambient temperature in flowing hydrogen before adding $\mathrm{CO}$ so as to produce a $1: 1 \mathrm{H}_{2} / \mathrm{CO}$ syngas feed with a total flow of $60 \mathrm{~mL} \mathrm{~min}{ }^{-1}$. Next, the total pressure was increased to 6 bar. Temperatures for the catalytic tests were approached using low heating rates of $1{ }^{\circ} \mathrm{C} \mathrm{min}^{-1}$. Catalytic activities and product selectivities $\left(\mathrm{CO}_{2}\right.$ included, if not otherwise mentioned) were determined at 250 and $300{ }^{\circ} \mathrm{C}$ in steadystate after stabilization for at least $12 \mathrm{~h}$. CO conversion and selectivities were determined by online gas chromatography and mass spectrometry (GC-MS, Agilent 7890A5975).

X-ray photoelectron spectroscopy (XPS) studies were carried out at a base pressure of about $5 \times 10^{-11} \mathrm{mbar}$. The XPS set-up was described in detail [45]. Colloidal solutions of FeRu nanoparticles were deposited onto a gold foil by drop casting. Prepared samples were first placed in the reaction chamber for degassing before transferring them into the analysis chamber under UHV conditions. The $\mathrm{X}$-ray source was operated with an acceleration voltage of $13 \mathrm{kV}$ and an emission current of $10 \mathrm{~mA}$. Non-monochromatized $\mathrm{Mg} \mathrm{K}$ radiation was used for the analysis and the $\mathrm{C} 1 s$ peak at $284.4 \mathrm{eV}$ was utilized as reference energy for charge correction. High resolution scans were made for $\mathrm{Fe} 2 p, \mathrm{C} 1 s, \mathrm{O} 1 s$ and Ru $3 d$ employing a pass energy of $50 \mathrm{eV}$ with a dwell time of $0.1 \mathrm{~s}$ and a step size of $0.05 \mathrm{eV}$.

For Microtomia experiments, followed by Transmission Electron Microscopy (TEM), the catalyst samples were directly embedded in an epoxy resin after degassing (Epon 812). Ultra-thin sections were cut on an UCT ultramicrotome (Leica Microsystems) at room temperature with a nominal thickness of $70 \mathrm{~nm}$ using an ultra $45^{\circ}$ diamond knife (Diatome Inc.). Samples were deposited on formvarcarbon-coated copper grids. TEM experiments were performed using a JEOL microscope (Model 1400F) working at $100 \mathrm{kV}$ electron acceleration voltage.

\section{Results and Discussion}

Catalytic measurements were performed under strictly differential conditions, i.e. at low $\mathrm{CO}$ conversion. Respective activity and selectivity data are compiled in Tables 1 and 2. Generally, catalyst samples become more active with increasing amounts of Ru. Literature reports which assign $\mathrm{Ru}$ metal a higher activity than $\mathrm{Fe}$ metal support this [18]. Moreover, as expected, the reaction rates are higher at $300{ }^{\circ} \mathrm{C}$ than at $250{ }^{\circ} \mathrm{C}$. The absolute rates need a critical assessment though. First, the preparation technique of our FeRu/MCF-17 samples does not guarantee the entire amounts of metal precursors to precipitate into nanoparticles. Furthermore, as shown below on account of our TEM studies, the samples obviously contain large crystal aggregates whose origin is not known at present. Such aggregates as well as soluble $\mathrm{Fe}$ and $\mathrm{Ru}$ organometallic complexes contribute to the AAS signals though. Their influence would be to decrease the rates normalized to unit amounts of $\mathrm{Fe}$ and $\mathrm{Ru}$.

The calculation of TOF values has become standard for assessing reaction rates in heterogeneous catalysis with metal nanoparticles. The procedures in doing so are not unambiguous though. While on the one hand reasonable assumptions on the particle morphology and metal site density can be made using microscopic evidence, this is much less so when it comes to assigning identical catalytic activity to all surface sites. With respect to the FischerTropsch synthesis, adsorbate-induced restructuring and sintering may occur as well. In the present case, the occurrence of FeRu bimetallic nanoparticles adds another level of complexity which led us to refrain from calculating TOF values but rather provide specific reaction rates by 
Table 2 Summarized data for catalytic properties of iron catalysts in high-pressure Fischer-Tropsch reaction (selectivities towards different products are shown in $\mathrm{wt} \%$ )

\begin{tabular}{|c|c|c|c|c|c|c|c|c|c|c|}
\hline \multirow[t]{2}{*}{ Sample } & \multirow[t]{2}{*}{ At.\% Ru (\%) } & \multirow{2}{*}{$\begin{array}{l}\text { Reaction rate, } \\
\left(\text { molecules }_{\mathrm{CO}} \mathrm{nm}^{-2} \mathrm{~s}^{-1}\right)\end{array}$} & \multicolumn{6}{|c|}{ Selectivity (\%) } & \multirow[t]{2}{*}{$\alpha \mathrm{RH}$} & \multirow[t]{2}{*}{$\alpha \mathrm{R}=$} \\
\hline & & & $\mathrm{CH}_{4}$ & $\mathrm{C}_{2}-\mathrm{C}_{4}$ & $\mathrm{C}_{2}=\mathrm{C}_{4}$ & $\mathrm{C}_{5+}$ & RO & $\mathrm{CO}_{2}$ & & \\
\hline FeRu1/MCF-17 & 5 & 0.005 & 32 & 2 & 37 & 6 & - & 23 & - & 0.39 \\
\hline FeRu2/MCF-17 & 17 & 0.008 & 19 & 10 & 20 & 27 & 12 & 11 & 0.71 & 0.35 \\
\hline FeRu3/MCF-17 & 33 & 0.036 & 19 & 9 & 19 & 25 & 16 & 11 & 0.65 & 0.40 \\
\hline FeRu1/MCF-17 & & & 42 & 2 & 48 & 10 & - & \multirow{3}{*}{\multicolumn{3}{|c|}{$\mathrm{CO}_{2}$ is excluded from the selectivity }} \\
\hline FeRu2/MCF-17 & & & 21 & 11 & 23 & 43 & 13 & & & \\
\hline FeRu3/MCF-17 & & & 22 & 10 & 21 & 39 & 18 & & & \\
\hline
\end{tabular}

$\mathrm{H}_{2}: \mathrm{CO}=1: 1,250{ }^{\circ} \mathrm{C}, 6$ bar, $\mathrm{D}_{\text {total }}=60 \mathrm{~mL} \mathrm{~min}^{-1}$

normalizing to the physical surface unit size. As discussed above, this procedure still leads to lower-limit rate data, and the true activities are likely higher than indicated.

As to the selectivities, it has to be kept in mind that they apply to low $\mathrm{CO}$ conversion. For example, measurements at $250{ }^{\circ} \mathrm{C}$ were performed with less than $0.5 \%$ conversion, those at $300{ }^{\circ} \mathrm{C}$ may eventually reach $3.5 \%$. Consequently, the statistical error is significant when calculating the amounts of longer-chain products at $250{ }^{\circ} \mathrm{C}$. Therefore, care is due when making cross comparisons between selectivities for both reaction temperatures, as compiled in Tables 1 and 2.

Despite the limitations as described above, it seems clear that Fe-rich nanoparticles (containing 5 at. $\% \mathrm{Ru}$ ) are able to produce considerable amounts of short-chain olefins. The ASF chain lengthening probability indicates formation of $\mathrm{C}_{\mathrm{n}}$ (terminal) olefins up to about $n=6$. Unfortunately, the selectivities of both methane and $\mathrm{CO}_{2}$ are quite high for these catalysts. We note that, without consideration of the $19 \%$ selectivity of $\mathrm{CO}_{2}$ formation, the $\mathrm{C}_{2-4}$ selectivity would approach values close to $50 \%$. This ranks our FeRu nanoparticles (with 5 at. $\% \mathrm{Ru}$ ) among the most active ones reported so far [21], in terms of olefin production.

An increase in $\mathrm{Ru}$ loading shifts the selectivity away from olefins towards paraffins at both temperatures, 250 and $300{ }^{\circ} \mathrm{C}$. This shift is associated with a considerable increase of the ASF chain lengthening probability. Thus, methane formation is not as dominating as in the case of $\mathrm{Fe}$-rich FeRu nanoparticles. Moreover, $\mathrm{CO}_{2}$ formation is abated with increasing $\mathrm{Ru}$ amounts. For FeRu catalysts containing 17 and 33 at.\% Ru, the selectivity to unwanted $\mathrm{CO}_{2}$ remains below $10 \%$. Obviously, the water gas shift reaction, $\mathrm{CO}+\mathrm{H}_{2} \mathrm{O} \rightarrow \mathrm{CO}_{2}+\mathrm{H}_{2}$, is of less concern for these catalysts. On the other hand, the production of oxygenates (dominated by terminal alcohols) is being detected for catalysts with high Ru content. This is somewhat surprising because some oxygenates formation would have also been expected for the Fe-rich catalyst sample.

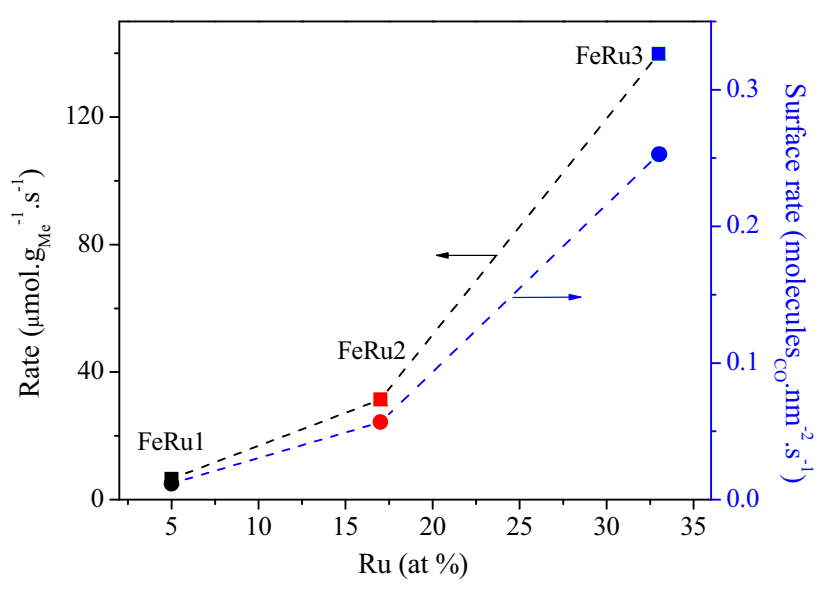

Fig. 1 Activity of iron-ruthenium catalysts with different compositions in Fischer-Tropsch reaction $\left(\mathrm{H}_{2}: \mathrm{CO}=1: 1,300{ }^{\circ} \mathrm{C}, 6\right.$ bar,

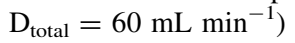

Cross comparisons with regard to the temperature dependence of the catalysts' chain lengthening properties have to be regarded with care. For example, it would have been expected that larger amounts of $\mathrm{C}_{5+}$ paraffins be obtained at $250{ }^{\circ} \mathrm{C}$ than at $300{ }^{\circ} \mathrm{C}$. This seems not to be the case here. We re-emphasize that the low $\mathrm{CO}$ conversion at $250{ }^{\circ} \mathrm{C}$ impacts the quantitative determination of longerchain products.

Summarizing the catalyst performance of our FeRu/ MCF-17 catalysts, we state, in accordance with expectations from literature for classical $\mathrm{Fe}$ - or $\mathrm{Ru}$-supported catalysts $[8-11,20,21,46]$, that nanoparticles rich in $\mathrm{Ru}$ are more active than those rich in Fe. This behavior is shown in Fig. 1. The absolute reaction rates have to be considered with care though; possible intricacies have been discussed above. Furthermore, considerable paraffin chain lengthening is observed for the former while short-chain terminal olefins are produced by the latter. The overall selectivity pattern for the catalysts is shown in Fig. 2. 


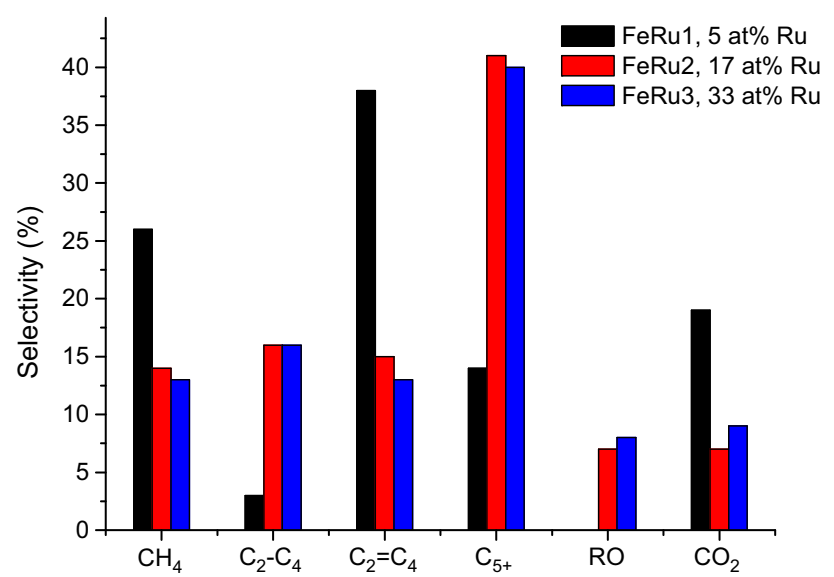

Fig. 2 Selectivity of iron-ruthenium catalysts with different compositions in Fischer-Tropsch reaction $\left(\mathrm{H}_{2}: \mathrm{CO}=1: 1,300{ }^{\circ} \mathrm{C}, 6\right.$ bar,

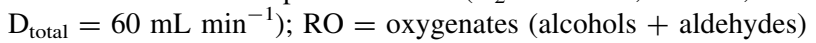

The remainder of the present communication is devoted to the characterization of our FeRu nanoparticles using XPS and microtomia/TEM. Ex-situ XPS studies were performed to determine the elemental composition close to the surface region. The results are shown in Fig. 3. Information about the occurrence of $\mathrm{O} 1 s$ and $\mathrm{C} 1 s$ in the samples is provided in the adhering table. Note that the integrated peak areas of these species are largely determined by the ex situ preparation of the samples. For the same reason, the $2 p$ Fe spectra in Fig. 3a are dominated by higher oxidation states (mainly $\mathrm{Fe}^{3+}$ ). The $3 d \mathrm{Ru}$ spectra seem also to be influenced by the ex situ preparation conditions, albeit less strongly than the $2 \mathrm{p} \mathrm{Fe}$ ones. The important information gleaned from Fig. 3 is that underparity amounts of $\mathrm{Ru}$ lead to a strong attenuation of the $\mathrm{Fe}$ $2 p$ photoemitted electrons. This can only be understood by assuming that $\mathrm{Ru}$ is intimately linked to $\mathrm{Fe}$ in FeRu nanoparticles and actually forms surface layers on top of these. Reciprocally, the $\mathrm{Ru} 3 d$ photoemission strongly increases with raising $\mathrm{Ru}$ amounts. Peak integration of the $\mathrm{Fe} 2 \mathrm{p}$ and $\mathrm{Ru} 3 d$ features, see the adjoining table, clearly shows the $\mathrm{Ru}$ surface enrichment relative to the nominal $\mathrm{Ru}$ amounts in the samples.

To provide information about the nanoparticles' dispersion after catalytic reaction studies, we performed microtomia experiments followed by TEM imaging. The results are shown in Fig. 4.

Interestingly we find that the distribution of the FeRu nanoparticles depends on the amount of ruthenium in these particles. At low $\mathrm{Ru}$ concentration $(\mathrm{Ru}=5$ at.\%), we observe that only a relatively small portion of the nanoparticles is retained inside the MCF-17 host while
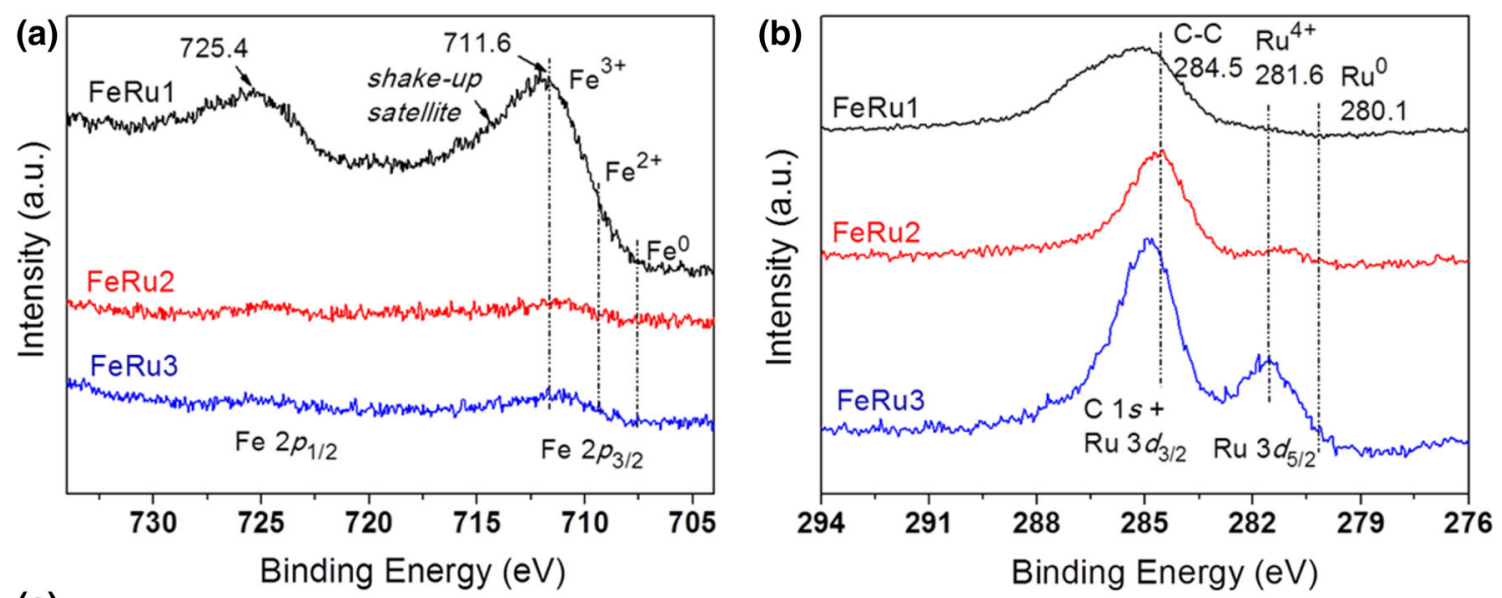

(c)

\begin{tabular}{|l|r|r|r|r|r|r|}
\hline Sample name & \% Fe 2p & \% Ru 3d & \% O 1s & \% C 1s & Fe/Ru & \multicolumn{1}{l|}{ \% Ru } \\
\hline FeRu1, 5 at\% Ru & 3.97 & 0.32 & 42.23 & 53.47 & 12.48 & 7.4 \\
\hline FeRu2, 17 at\% Ru & 1.22 & 1.31 & 21.23 & 76.24 & 0.932 & 52 \\
\hline FeRu3, 33 at\% Ru & 0.87 & 2.78 & 22.31 & 74.04 & 0.315 & 76 \\
\hline
\end{tabular}

Fig. 3 XPS studies performed on iron-ruthenium catalysts with different compositions a $2 p$ Fe spectra, b $3 d$ Ru spectra, $\mathbf{c}$ peak integration of the $2 p \mathrm{Fe}$ and $3 d \mathrm{Ru}$ features 

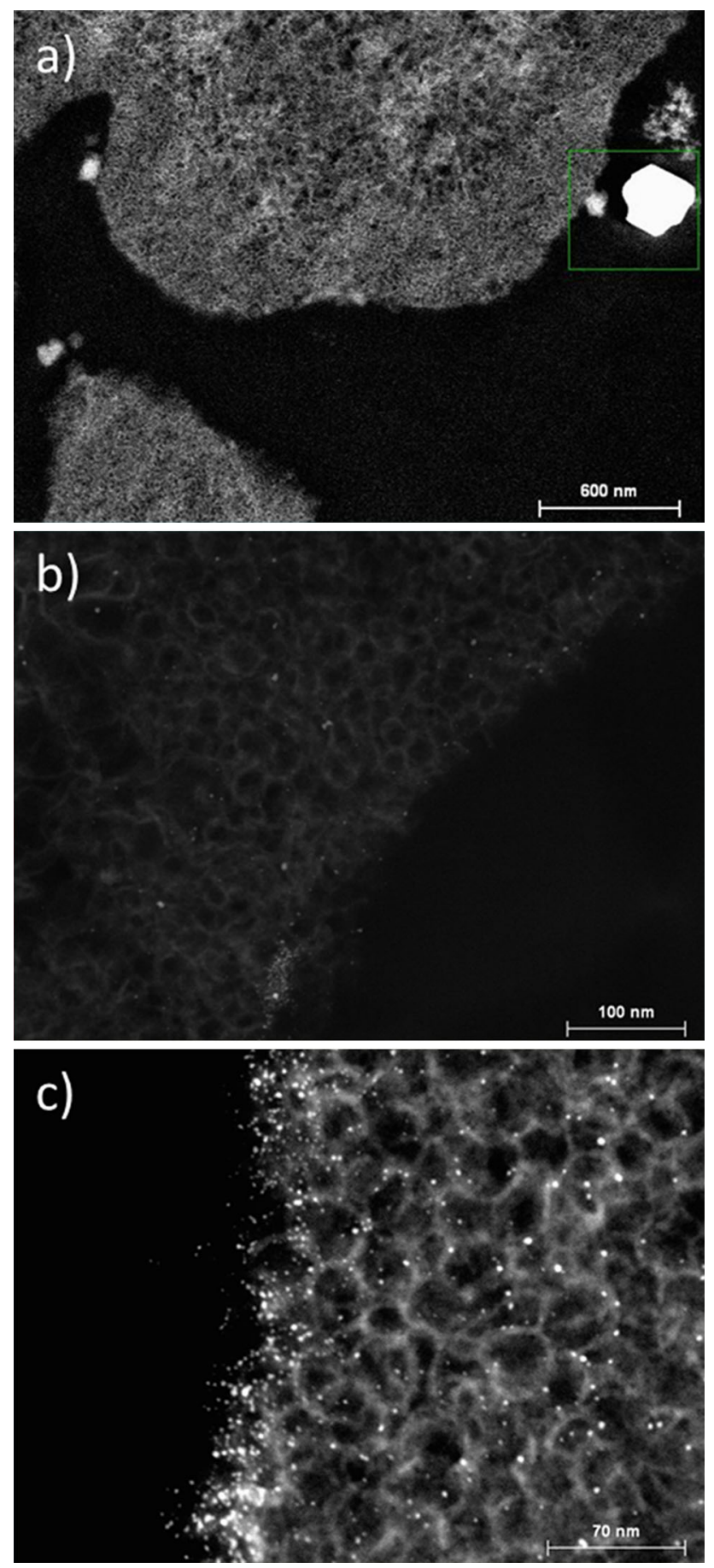

Fig. 4 TEM images after Microtomia of a FeRu1, b FeRu2, c FeRu3. All samples were characterised after FT catalysis

substantial amounts are agglomerated in the outer surface region (see Fig. 4a). By contrast, nanoparticles with higher $\mathrm{Ru}$ concentration (17 and 33 at.\%, respectively) remain located inside the silica and do not show significant size changes compared to the initial impregnating solutions (see Fig. 4b, c). Additionally, in the case of FeRu2 (17 at.\%),
EDX (energy dispersive X-ray spectroscopy) results indicate the presence of both metals in the nanoparticles (see Fig. 2 Supporting Information). This demonstrates that ruthenium-rich nanoparticles derived from organometallic complexes are stable in the pores during FT catalysis. The origin of this stabilization is not clear though. The occurrence of ruthenium on the surface of iron nanoparticles may inhibit the coalescence of the particles by rendering them less prone to chemical phase transformations as encountered for pure iron-based catalysts. As a matter of fact, while $\mathrm{Fe}$ is subject to bulk carbide and oxide formation under reaction conditions-with the "true" surface composition remaining a matter of debate- $\mathrm{Ru}$ is much less so, if at all. Therefore, in view of the large water production during FT synthesis, much less surface water/ hydroxyl-mediated coalescence is expected to occur for $\mathrm{Ru}$-rich rather than for Ru-poor FeRu nanoparticles. These ideas remain speculation at present. More detailed characterisation is necessary to arrive at scientifically sound conclusions.

In conclusion, this study shows that bimetallic nanoparticles prepared following an organometallic route can be successfully inserted into a mesoporous silica without any pre- or post-treatment. Such model catalysts display interesting catalytic properties in the absence of classical activation routes. Further research with organometallic precursors will explore the full potential of this approach for catalytic reaction studies.

\section{References}

1. van der Laan GP, Beenackers AACM (1999) Catal Rev Sci Eng $41: 255-318$

2. Abello S, Montané D (2011) ChemSusChem 4:1538-1556

3. Khodakov AY, Chu W, Fongarland P (2007) Chem Rev 107:1692-1744

4. Bezemer GL, Bitter JH, Kuipers HPCE, Osterbeek H, Holewijn JE, Xu X, Kapteijn F, Van Dillen AJ, de Jong KP (2006) J Am Chem Soc 128:3956-3964

5. Chen W, Fan Z, Pan X, Bao X (2008) J Am Chem Soc 130:9414-9419

6. Xiao C, Cai Z, Wang T, Kou Y, Yan N (2008) Angew Chem Int Ed 47:746-749

7. Bao J, He J, Zhang Y, Yoneyama Y, Tsubaki N (2008) Angew Chem Int Ed 47:353-356

8. Quek XY, Guan Y, van Santen RA, Hensen EJM (2011) ChemCatChem 3(11):1735-1738

9. Xiang Y, Chitry V, Liddicoat P, Felfer P, Cairney J, Ringer S, Kruse N (2013) J Am Chem Soc 135(19):7114-7117

10. Graham UM, Jacobs G, Gnanamani MK, Lipka SM, Shafer WD, Swartz CR, Jermwongratanachai T, Chen R, Rogers F, Davis BH (2014) ACS Catal 1662-1672

11. Liu JJ, Guo Z, Childers D, Schweitzer N, Marshall CL, Klie RF, Miller JT, Meyer RJ (2014) J Catal 313:149-158

12. Reuel RC, Bartholomew CH (1984) J Catal 85:78-88 
13. Lisitsyn AS, Golovin AV, Kuznetsov VL, Yermakov YI (1985) J Catal 95:527-538

14. Iglesia E (1997) Appl Catal A 161:59-78

15. Borg O, Walmsley JC, Dehghan R, Tanem BS, Blekkan EA, Eri S, Rytter E, Holmen A (2008) Catal Lett 126:224-230

16. Borg O, Dietzel PDC, Spjelkavik AI, Tveten EZ, Walmsley JC, Dislas S, Eri S, Holmen A, Rytter E (2008) J Catal 259:161-164

17. Kellner CS, Bell AT (1982) J Catal 75(2):251-261

18. Kang J, Zhang S, Zhang Q, Wang Y (2009) Angew Chem Int Ed 48(14):2565-2568

19. Carballo JMG, Yang J, Holmen A, Garcia-Rodriguez S, Rojas S, Ojeda M, Fierro JLG (2011) J Catal 284(1):102-108

20. Torres Galvis HM, Bitter JH, Davidian T, Ruitenbeek M, Dugulan AI, de Jong KP (2012) J Am Chem Soc 134(39):16207-16215

21. Torres Galvis HM, Bitter JH, Khare CB, Ruitenbeek M, Dugulan AI, de Jong KP (2012) Science 335(6070):835-838

22. Ott GL, Fleich T, Delgass WN (1979) J Catal 60:394-403

23. Ott GL, Fleich T, Delgass WN (1980) J Catal 65:253-262

24. Berry FJ, Liwu L, Chengyu W, Renyuan T, Su Z, Dongbai L (1985) J Chem Soc, Faraday Trans 1(81):2293-2305

25. Bahome MC, Jewell LL, Padayachy K, Hildebrandt D, Glasser D, Datye AK, Coville NJ (2007) Appl Catal A 328:243-251

26. Du JQ, Zhang Y, Tian T, Yan SC, Wang HT (2009) Mater Res Bull 44:1347-1351

27. Bachiller-Baeza B, Guerrero-Ruiz A, Wang P, Rodriguez-Ramos I (2001) J Catal 204:450-459

28. Andanson JM, Marx S, Baiker A (2012) Catal Sci Technol 2:1403-1409

29. Lazar K, Reiff WM, Morke W, Guczi L (1986) J Catal 100:118-129

30. Kannan KR, Kulkarni GU, Rao CNR (1992) Catal Lett $14: 149-163$

31. Wang X, Yue W, He M, Liu M, Zhang J, Liu Z (2004) Chem Mater 16:799-805
32. Popovska N, Danova K, Jipa I, Zenneck U (2011) Powder Technol 207:17-25

33. Kelsen V, Meffre A, Fazzini PF, Lecante P, Chaudret B (2014) ChemCatChem 6:1714-1720

34. Kelsen V, Wendt B, Werkmeister S, Junge K, Beller M, Chaudret B (2013) Chem Commun 49:3416-3418

35. Meffre A, Lachaize S, Gatel C, Respaud M, Chaudret B (2011) J Mater Chem 21:13464-13469

36. Dumestre F, Chaudret B, Amiens C, Renauld P, Fejes P (2004) Science 303:821-823

37. Ciuculescu D, Amiens C, Respaud M, Falqui A, Lecante P, Benfield RE, Jiang L, Fauth K, Chaudret B (2007) Chem Mater 19:4624-4626

38. Meffre A, Mehdaoui B, Kelsen V, Carrey J, Lachaize S, Fazzini PF, Respaud M, Chaudret B (2012) Nano Lett 12(9):4722-4728

39. Mehdaoui B, Meffre A, Lacroix LM, Carrey J, Lachaize S, Goujeon M, Respaud M, Chaudret B (2011) Adv Funct Mater 21:4573-4581

40. Mehdaoui B, Meffre A, Lacroix LM, Carrey J, Lachaize S, Goujeon M, Respaud M, Chaudret B (2010) J Magn Magn Mater 332:L49-L52

41. Mehdaoui B, Meffre A, Lacroix LM, Carrey J, Lachaize S, Gougeon M, Respaud M, Chaudret B (2010) J Appl Phys 107(3):09A324

42. Mehdaoui B, Tan RP, Meffre A, Carrey J, Lachaize S, Chaudret B, Respaud M (2013) Phys Rev B 87(10):174419

43. Monza A, Meffre A, Baudelet F, Rueff JP, d'Astuto M, Munsch P, Huotari S, Lachaize S, Chaudret B, Shukla A (2011) Phys Rev Lett 106(4):247201

44. Dugay J, Tan RP, Meffre A, Blon T, Lacroix LM, Carrey J, Fazzini PF, Lachaize S, Chaudret B, Respaud M (2011) Nano Lett 11:5128-5134

45. Chenakin SP, Prada SR, Kruse N (2005) J Phys Chem B 109:14611-14618

46. Vannice MA (1976) Catal Rev 14:153 